\title{
西双版纳片断热带雨林植物区系 成分及变化趋势
}

\author{
朱 华 许再富 王 洪 李保贵 \\ (中国科学院西双版纳热带植物园昆明分部, 昆明 650223)
}

\begin{abstract}
摘 要 本文以西双版纳地区的 6 个 龙山”片断热带雨林的植物物种多样性编目为基础, 通过与同样 类型的原始热带雨林的比较, 探讨了片断热带雨林植物区系成分的变化。随着热带雨林的片断化, 森林 边缘效应和人为干扰加剧, 阳性先锋植物和藤本植物等的侵入, 导致这些先锋植物和藤本植物所属的科 属在群落中的种数增多, 优势度增大。而一些含喜荫湿的荫生植物、群落顶极树种及附生植物较多的科 属则在群落中的种数减小了, 优势度下降。在植物属的地理成分构成上, 片断热带雨林中全热带分布和 热带亚洲一热带非洲分布成分比例相对增高, 而热带亚洲成分相对减少。在种的地理成分构成上,片断 热带雨林中广域分布种比例相对增高, 显示了与属的地理成分类似的变化。这也是森林片断化后, 由于 边缘效应和林内生境在一定程度上干暖化, 喜光的先锋成分增多, 而先锋成分大多为一些广域分布属种 所致。
\end{abstract}

\section{关键词 片断热带雨林, 植物区系成分, 西双版纳}

Floristic composition and change of rain forest fragments in Xishuangbanna, southern Yunnan / ZHU hua, XU Zai Fu, WANG Hong, LI Bao- Gui

Abstract Floristic inventories of six rain forest fragments on Holy Hills of Dai people in Xishuangbanna, southern Yunnan, were made. Change in floristic composition of the fragments was analyzed based on the comparison with the continuous primary rain forest of the region. With fragmentation and growing disturbances on the rain forest fragments, some plant families, such as Papilionaceae, Rutaceae and Euphorbiaceae, conspicuously increased in relative number of species or species percentage, while some families such as Ochidaceae, Lauraceae, Annonaceae and Urticaceae, decreased in relative number of pecies, i. e. their formerdominance faded owing to the invasion of a lot of pioneers and declination or extinction of shande tolerant and climax species. In composition of geographical elements of the flora of fragments, the elements of pantropicand tropical Asia to tropical Africa distributions increased in percentage at genus level and those of wide distri-bur tion increased, while those of the usually limited or local distribution decreased at pecies level.

Key words rain forest fragments, floristic composition, southern Yunnan

Author' s address Kunming Division of Xishuangbanna Tropical Botanical Garden, Chinese Academy of Sciences, Kunming 650223

热带地区生境破碎化和热带森林片断化已不可避免, 热带森林片断化与生物多样性关系 的研究是目前国际上对热带森林生物多样性保护研究的核心和焦点 (Bierregaard \& Lovejoy, 1989 ; Klein ,1989 ;Leigh et al. ,1993;Laurance , 1994 ; Kattan et al. , 1994 ;Fonseca et al. ,1994; Turner ,1996;Laurance \& Bierregaard, 1997; Fox et al. ,1997;Malanson \& Cairns ,1997)。目 前对片断化热带森林的研究主要集中在所谓的边缘效应对森林小环境和生物多样性各个方面 的影响上 (Malcom, 1994 ;Laurance ,1991; Laurance et al. ,1998; Murcia ,1995; Williams-Linera，

* 云南省基金 98C $096 \mathrm{M}, 96 \mathrm{C} 122 \mathrm{M}$, 中国科学院 KZ951-A-104 课题, 中国科学院百人计划, 国家科委 14-602 支持项目 收稿日期:1999- 09 - 08 ;修改稿收到日期:2000 - 02 - 29 
1992 ; Oliveira- Filho et al. ,1997)，已发表了很多研究论文。然而,就片断化的热带森林的植物 区系成分的变化研究, 还未见有过报道, 而植物区系组成正是生物多样性编目的核心内容, 无 疑对热带森林生物多样性保护研究亦有十分重要的意义。

西双版纳傣族的“龙山”作为一种少数民族的神山或坟山, 大多保存了一些原始森林的片 段。在周围附近原始植被已不复存在的今天, 龙山上的森林片断不但是残存下来的珍贵的原 生森林和种质资源, 而且在生物多样性保护和当地原始植被和植物区系的研究上具有十分重 要的意义。西双版纳傣族的龙山主要分布在坝区海拔 $800 \mathrm{~m}$ 以下的低丘山地和低平地上, 龙 山上残留的森林原始地主要属于热带季节雨林类型(朱华等, 1993)。经过对西双版纳地区现 存的龙山林进行了初步的勘察后, 我们选择了位于预腊县的曼龙龙山、敌仑曼俄龙山、预仑城 子龙山和景洪县的大敌龙曼养广龙山、曼养龙山和曼远龙山进行了植物区系组成和植被的本 底调查, 对群落组成、结构及物种多样性等各个方面进行了初步研究, 并与同样植被类型的原 始热带雨林(预仑自保护区)作比较,结合隔离和环境状况,探讨龙山片断雨林的物种多样性变 化的规律 (朱华等, 1997)。通过比较研究, 对面积较大和保存相对好的 3 个龙山林, 即预仑曼 俄龙山林(约 $3 \mathrm{hm}^{2}$ )、㔚仑城子龙山林(约 $4 \mathrm{hm}^{2}$ ) 和大预龙曼养广龙山林(约 $13 \mathrm{hm}^{2}$ ), 我们还 进行了环境包括小气候、土壤条件的研究测试，进行了乌类、鼠类、两栖爬行类、昆虫及土壤动 物等物种多样性变化的研究(许再富等, 1998)。在中国科学院 95 重大项目的支持下, 针对生 境片断化与生物多样性丧失, 我们对这几个龙山片断热带雨林进一步从物种的遗传多样性、土 壤微生物、动物 - 植物关系、边缘效应等方面深入进行研究。本文以进行了详细植物区系组成 调查的 6 个龙山片断热带雨林为基础, 从植物区系组成和区系成分的变化上探讨片断热带雨 林植物多样性及其变化, 为西双版纳傣族的龙山片断热带雨林生物多样性的研究提供必要的 基础数据资料和补充。

\section{1 植物多样性的组成}

经过对所选 6 个龙山林的植物区系采集调查,共记录有维管植物 95 科 278 属 413 种及变 种, 其中种子植物占 78 科 244 属 362 种和变种, 偋类植物 17 科 31 属 51 种。

种子植物中, 含 10 种以上的大科有 10 个, 按种数排列名称为茜草科(Rubiaceae, 17 属 $/ 35$ 种),大韩科(Euphorbiaceae, 15/23)，桑科(Moraceae, 6/18), 蝶形花科(Papilionaceae, 6/17), 樟 科(Lauraceae, 7/14), 芸香科 (Rutaceae, 7/14), 夹竹桃科 (Apocynaceae, 12/13), 楝科 (Meliaceae, $8 / 13$ ), 爵床科 (Acanthacee, $9 / 10$ )，番荔枝科 (6/10); 含 $6 \sim 9$ 种的科有 8 个; 含 $2 \sim 5$ 种 的科有 39 个; 含 1 种的科有 21 个。种子植物中, 平均每科仅 4.65 种, 与西双版纳植物区系 平均每科 16.9 种相比显然少得多, 与原始热带雨林植物区系平均每科 5.8 种相比亦偏少, 大 多数科均为 5 种以下的科。

在该植物区系的 244 个种子植物属中, 有单型属 9 个 $^{*}$, 如大戟科的缅桐属 (Sumbaviopsis), 茶荣英科的麻核藤属 (Natsiatopsis), 漆树科的南酸東属 (Choerospondias), 紫藏科的火烧 花属 (Mayodendron)，蝶形花科的巴豆藤属 (Craspedolobium)，四树木科的四树木属(Tetrameles)等; 有少型属 21 个, 单型属与少型属各占 $4.1 \%$ 和 $9.5 \%$; 有小属和中属 137 个, 而含 100 种以上的大属有 77 个。与西双版纳植物区系单型属占总属数的 $5.2 \%$,少型属占总数的

* 单型属:全属仅含 1 种;少型属:全属含 $2 \sim 6$ 种; 小属:全属含 $7 \sim 15$ 种; 中属:全属含 $16 \sim 100$ 种; 大属: 全属含 100 种以 上 
$15.4 \%$ 相比, 单型属略有减少, 少型属则明显减少。单型属和少型属通常是较古老和孤立的成 分 (吴征镒, 王荷生, 1983), 意味着较古老和孤立的成分在生境片断化过程中更易散失, 在生物 多样性保护上应给予特别注意。

\section{2 植物区系的地理成分}

\section{1 种子植物科的地理成分}

在地理成分构成上, 在种子植物科水平, 典型热带科有 12 个, 占总科数的 $15.4 \%$, 如泛热 带的牛栓藤科 (Connaraceae)、肉豆冦科 (Myristicaceae)、橄榄科 (Bursseraceae)、山榄科 (Sapotaceae)、茶茶英科(Icacinaceae) 等, 古热带的露樂树科(Pandanaceae), 热带亚洲分布的四 数木科(Tetrameleaceae), 热带亚、非、美洲分布的粘木科(Ixonanthaceae)等。主产热带,但分布 区延伸到亚热带甚至温带的科有 51 个,占 $65.4 \%$,如茜草科、大戟科、桑科、樟科、夹竹桃科、 楝科、芸香科、爵床科、番荔枝科(Anonaceae)、无患子科(Sapindaceae)、葡萄科(Vitaceae)、天南 星科 (Araceae)、灰木科 (Symplocaceae) 等。主产亚热带的科有 7 个, 占 $9 \%$, 如壳斗科 ( $\mathrm{Fa}$ gaceae)、木兰科(Magnoliacae)、山茶科(Theaceae)等。全世界分布或主产温带的科有 8 个,占 $10.3 \%$, 主要是些草本科, 如菊科 (Compositae)、玄参科 (Scrophularicaceae)、禾本科 (Gramineae)等。

\section{表 1 片断雨林与原始雨林植物区系属的分布类型}

Table 1 The distribution types of the genera from the fragmentary forests and the continuous primary forest

\begin{tabular}{|c|c|c|c|}
\hline \multirow{2}{*}{$\begin{array}{l}\text { 分布 类 型 } \\
\text { Distribution type }\end{array}$} & \multicolumn{2}{|c|}{$\begin{array}{c}\text { 片断雨林 } \\
\text { Fragmentary forest }\end{array}$} & \multirow{2}{*}{$\begin{array}{c}\begin{array}{c}\text { 原始雨林 } \\
\text { Primary forest }\end{array} \\
\text { 百分比 }(\%) \\
\text { Percentage }\end{array}$} \\
\hline & $\begin{array}{l}\text { 属数 } \\
\text { No. of genera }\end{array}$ & $\begin{array}{l}\text { 百分比 }(\%) \\
\text { Percentage }\end{array}$ & \\
\hline \multicolumn{4}{|l|}{ 1.全世界分布 } \\
\hline $\begin{array}{l}\text { Cosmopolitan } \\
\text { 2. 全热带分布 }\end{array}$ & 3 & 1.4 & 0 \\
\hline $\begin{array}{l}\text { Pantropic } \\
\text { 3. 热带亚洲至热带美洲间断分布 }\end{array}$ & 62 & 25.4 & 19.7 \\
\hline $\begin{array}{l}\text { Tropical Asia and Tropical America disjunct } \\
\text { 4. 旧世界热带分布 }\end{array}$ & 11 & 4.5 & 4.3 \\
\hline $\begin{array}{l}\text { Old world Tropics } \\
\text { 5. 热带亚洲至大洋洲 }\end{array}$ & 33 & 13.6 & 14.2 \\
\hline $\begin{array}{l}\text { Tropical Asia to Tropical Australia } \\
\text { 6. 热带亚洲至热带非洲分布 }\end{array}$ & 24 & 10 & 9.2 \\
\hline $\begin{array}{l}\text { Tropical Asia to Tropical Africa } \\
\text { 7. 热带亚洲分布 }\end{array}$ & 18 & 7.2 & 4.8 \\
\hline $\begin{array}{l}\text { Tropical Asia } \\
\text { 8. 北温带分布 }\end{array}$ & 81 & 33.2 & 42.5 \\
\hline $\begin{array}{l}\text { N. Temperate } \\
\text { 9. 东亚一北美间断分布 }\end{array}$ & 5 & 1.9 & 1.8 \\
\hline $\begin{array}{l}\text { E. Asia and N. America disjunct } \\
\text { 10. 东亚分布 }\end{array}$ & 3 & 1.4 & 1.8 \\
\hline $\begin{array}{l}\text { E. Asia } \\
\text { 11. 中国特有分布 }\end{array}$ & 3 & 1.4 & 0.3 \\
\hline Endemic to China & 1 & 0.5 & 1.5 \\
\hline 合计 Total & 244 & 100 & 100 \\
\hline
\end{tabular}




\section{2 种子植物属的地理成分}

在属水平上,按照吴征镒教授对中国种子植物属分布区类型的划分 (吴征镒,19991)，该植 物区系属的地理成分构成是: 热带分布属 (类型 2 - 7) 共计 229 个,占总属数的 $93.9 \%$; 温带 分布属(类型 8 和 9) 有 8 个, 仅占 $3.3 \%$; 其它是东亚和中国特有共 4 个, 世界广布属 3 个。在 热带分布属中, 又以热带亚洲分布属最多, 有 81 个, 占 $33.2 \%$; 其次是全热带分布属 62 个, 占 $25.3 \%$; 旧世界热带分布属 33 个以及热带亚洲至大洋洲分布属 24 个, 热带亚洲至热带非洲分 布属 18 个等(表 1 )。

\section{3 种的地理成分构成}

通过查阅有关分类群的专著和文献资料, 对傣族龙山片断雨林 315 种种子植物的分布作 了研究, 然后根据各个种的地理分布式样, 参考植物区系的分区和发生特征, 将它们归纳为 9 个分布区类型, 6 个变型 (表 2)。变型是在分布类型范围内根据各分布式样局限在一定的地 理区域, 分布区或大或小, 但有共同的发生特性的区分。

\section{表 2 片断雨林与原始雨林植物区系种的分布类型}

Table 2 The distribution type of the species from the fragmentary forests and the continuous primary forests

种分布区类型

Distributional types of species
片断雨林

Fragmentary forest 原始雨林 Primary forest

种数 百分比 (\%)百分比 (\%)

No. sp. Percentage Percentage

\begin{tabular}{lccc}
\hline 泛热带分布 Pantropic & 1 & 0.3 & 0 \\
热带亚洲至热带美洲分布 Tropical Asia and tropical America disjunct & 1 & 0.3 & 0 \\
旧世界热带分布 Old World Tropics & 2 & 0.6 & 0.3 \\
热带亚洲至大洋洲分布 Tropical Asia to Tropical Australia & 10 & 3.2 & 2.9 \\
热带亚洲至热带非洲分布 Tropical Asia to Tropical Africa & 7 & 2.2 & 0 \\
\hline 热带亚洲分布及其变型 Tropical Asia and its varieties & $(235)$ & $(74.6)$ & $(73.3)$ \\
1.印度一马来西亚 India- Malesia & 87 & 27.6 & 21.2 \\
2. 大陆东南亚一马来西亚(东南亚分布) Mainland SE. Asia to Malesia & 26 & 8.3 & 7.5 \\
3. 南亚一大陆东南亚 S. Asia to Mainland SE. Asia & 61 & 19.4 & 21.3 \\
4. 大陆东南亚至华南 Mainland SE. Asia to S. China & 61 & 19.4 & 23.5 \\
\hline 中国西南至东南部分布 SW. to SE. China & 12 & 3.8 & 1.7 \\
1. 云南、广西 (或广东南部)、海南热带 & & & 3.4 \\
Tropical areas of S. Yunnan, Guangxi (S. Guangdong) and Hainan & 11 & 3.5 & 3.1 \\
2. 云南广广西或贵州南部热带至亚热带 & & & \\
$\quad$ Tropical to subtropical areas of Yunnan, Guangxi or S. Guizhou & 9 & 2.8 & 3.1 \\
\hline 云南特有分布 Endemic to Yunnan & 17 & 5.4 & 10.2 \\
西双版纳特有分布 Endemic to Xishuangbanna & 10 & 3.2 & 5.1 \\
\hline$\quad$ 总计 Total & 315 & 100 & 100 \\
\hline
\end{tabular}

种的分布区类型或地理成分构成显然以热带亚洲分布及其变型为主体, 有 235 种, 占总种 数的 $74.6 \%$, 其中又具体以印度一马来西亚分布为多,占总种数的 $27.6 \%$ 。若加上中国热带 北缘地区分布的种类, 热带成分超过 $90 \%$ 。

无论属和种的地理成分发构成仍以热带成分占绝对优势, 龙山片断雨林的热带性质和特 点仍是明显的。 


\section{1 植物区系优势科的变化}

我们把龙山片断热带雨林植物区系的前 17 名优势科与该地区原始热带雨林植物区系的 优势科作了比较,结果列于表 3。片断热带雨林的优势科大多数仍在原始热带雨林的优势科 之列, 但有些科的排名和所含种数百分比发生了变化。例如, 蝶形花科和芸香科排名前移和种 数百分比明显增大; 大戟科、桑科、爵床科、夹竹桃科排名亦有所前移和种数百分比增大; 紫金 牛科、夢摩科、鼠李科、无患子科、含羞草科等跃居排名在前的优势科之列。而在原始热带雨林 植物区系优势科之列中的樟科和番荔枝科, 在片断热带雨林中排名有所后移和种数百分比减 小; 兰科、壳斗科、天南星科、胡椒科、杜英科已不在片断热带雨林的优势科之列; 莳麻科则几乎 从片断热带雨林中消失了。随着热带雨林的片断化, 森林边缘效应和人为干扰加剧, 阳性先锋 植物如蝶形花科崖豆树属 (Millettia) 植物多种、大戟科血桐属 (Macaranga) 和野桐属 (Mallo$t u s$ ) 植物多种及芸香科黄皮属 (Clausena) 植物等大量侵入, 导致这些先锋植物所隶属的科在 群落中的优势度增大。同样, 由于边缘效应, 藤本植物在林缘大量增加, 导致一些含藤本植物 多的科如萝摩科、夹竹桃科等亦在群落中的优势度增大。相反, 一些含喜荫湿的荫生植物较多 的科如胡椒科、菖麻科等,一些含群落顶极树种较多的科如壳斗科、樟科、番荔枝科、杜英等, 以 及一些含附生植物较多的科如天南星科、兰科等则在群落中的优势度减小了。

\section{表 3 西双版纳“龙山”片断热带雨林与原始热带雨林种子植物优势科的比较}

Table 3 Comparison of dominant families between the fragmentary tropical rain forests on Dai's Holy Hills and the primary rain forest of Xishuangbanna

\begin{tabular}{|c|c|c|c|c|c|c|c|c|c|c|c|}
\hline \multicolumn{6}{|c|}{ 片断热带雨林 Fragmentary tropical rain forest } & \multicolumn{6}{|c|}{ 原始热带雨林 Primary tropical rain forest } \\
\hline $\begin{array}{l}\text { 排名 } \\
\text { Rank }\end{array}$ & & $\begin{array}{l}\text { 名 } \\
\text { mily }\end{array}$ & $\begin{array}{l}\text { 种数 } \\
\text { No. } \\
\text { of sp. }\end{array}$ & $\begin{array}{c}\text { 片断 } \\
\text { 雨林 } \\
\text { Frag- } \\
\text { m. (\%) }\end{array}$ & $\begin{array}{c}\text { 原始 } \\
\text { 雨林 } \\
\text { Cont. } \\
(\%) \\
\end{array}$ & $\begin{array}{l}\text { 排名 } \\
\text { Rank }\end{array}$ & & $\begin{array}{l}\text { 名 } \\
\text { mily }\end{array}$ & $\begin{array}{l}\text { 种数 } \\
\text { No. } \\
\text { of sp. }\end{array}$ & $\begin{array}{c}\text { 片断 } \\
\text { 雨林 } \\
\text { Frag- } \\
\text { m. (\%) }\end{array}$ & $\begin{array}{c}\text { 原始 } \\
\text { 雨林 } \\
\text { Cont. } \\
(\%) \\
\end{array}$ \\
\hline 1 & 茜草科 & Rubiaceae & 35 & 9.67 & 8.32 & 1 & 茜草科 & Rubiaceae & 53 & 8.32 & 9.67 \\
\hline 2 & 大戟科 & Euphorbiaceae & 23 & 6.35 & 4.40 & 2 & 樟 科 & Lauraceae & 35 & 5.49 & 3.87 \\
\hline 3 & 桑科 & Moraceae & 18 & 4.97 & 3.29 & 3 & 大戟科 & Euphorbiaceae & e 28 & 4.40 & 6.35 \\
\hline 4 & 蝶形花科 & Papilionaceae & 17 & 4.70 & 1.73 & 4 & 番荕枝科 & Anonaceae & 28 & 4.40 & 2.76 \\
\hline 5 & 樟科 & Lauraceae & 14 & 3.87 & 5.49 & 5 & 桑 科 & Moraceae & 25 & 3.92 & 4.97 \\
\hline 6 & 芸香科 & Rutaceae & 14 & 3.87 & 1.88 & 6 & 兰科 & Ochidaceae & 23 & 3.61 & 0.28 \\
\hline 7 & 夹竹桃科 & Apocynaceae & 13 & 3.59 & 2.04 & 7 & 棟科 & Meliaceae & 22 & 3.45 & 3.59 \\
\hline 8 & 栋科 & Meliaceae & 13 & 3.59 & 3.45 & 8 & 葡萄科 & Vitaceae & 15 & 2.35 & 2.21 \\
\hline 9 & 爵床科 & Acanthaceae & 10 & 2.76 & 1.73 & 9 & 夹竹桃科 & Apocynaceae & 13 & 2.04 & 3.59 \\
\hline 10 & 番荔枝科 & Anonaceae & 10 & 2.76 & 4.40 & 10 & 芸香科 & Rutaceae & 12 & 1.88 & 3.87 \\
\hline 11 & 紫金牛科 & Myrsinaceae & 9 & 2.49 & 1.41 & 11 & 菖麻科 & Urticaceae & 12 & 1.88 & 0 \\
\hline 12 & 萝摩科 & Asclepiadaceae & e 8 & 2.21 & 1.10 & 12 & 壳斗科 & Fagaceae & 12 & 1.88 & 0.55 \\
\hline 13 & 葡萄科 & Vitaceae & 8 & 2.21 & 2.35 & 13 & 蝶形花科 & Papilionaceae & 11 & 1.73 & 4.7 \\
\hline 14 & 鼠李科 & Rhamnaceae & 7 & 1.93 & 0.94 & 14 & 爵床科 & Acanthaceae & 11 & 1.73 & 2.76 \\
\hline 15 & 无患子科 & Sapindaceae & 7 & 1.93 & 0.63 & 15 & 天南星科 & Araceae & 10 & 1.57 & 1.38 \\
\hline 16 & 五加科 & Araliaceae & 6 & 1.66 & 1.26 & 16 & 胡椒科 & Piperaceae & 10 & 1.57 & 0.83 \\
\hline 17 & 含羞草科 & Mimosaceae & 6 & 1.66 & 0.94 & 17 & 杜英科 & Elaeocarpaceae & 10 & 1.57 & 0.83 \\
\hline
\end{tabular}




\section{2 植物区系地理成分的变化}

西双版纳傣族龙山片断热带雨林植物区系属和种的地理成分构成与原始热带雨林的比较 见图 1 和图 2 。在属的地理成分上,片断热带雨林中全热带分布和热带亚洲至热带非洲分布 成分比例相对增高, 而热带亚洲成分相对减少, 这似乎是森林片断化后, 由于边缘效应和林内 生境在一定程度上干暖化, 喜光的先锋成分增多, 而先锋成分大多为一些广域分布属。在种的 地理成分上,片断热带雨林中广域分布种比例相对增高, 显示了与属的地理成分类似的变化。

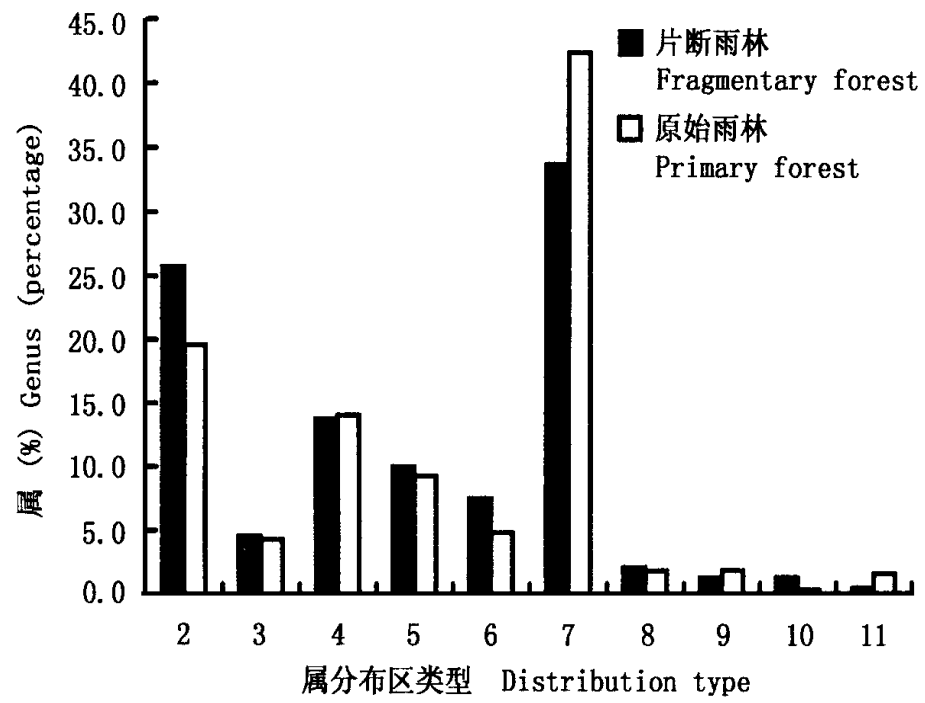

\begin{abstract}
2. 全热带分布; 3. 热带亚洲至 热带美洲间断分布; 4 . 旧世界热 带分布; 5 . 热带亚洲至大洋洲分 布; 6. 热带亚洲至热带非洲分 布;7. 热带亚洲分布; 8. 北温带 分布; 9 . 东亚一北美间断分布; 10. 东亚分布; 11 . 中国特有分 布。

2. Pantropic; 3 . Tropical Asia and Tropical America disjunct; 4. Old World Tropics; 5. Tropical Asia and Tropical Australia;6. Tropical Asia to Tropical Africa; 7. Tropical Asia; 8. North Temperate; 9. East Asia and North America disjunct; 10. East Asia; 11. Endemic to China.
\end{abstract}

图 1 片断雨林与原始雨林植物区系属地理成分比较

Fig. 1 Comparison of distribution types of genera between the fragments and continuous primary forests

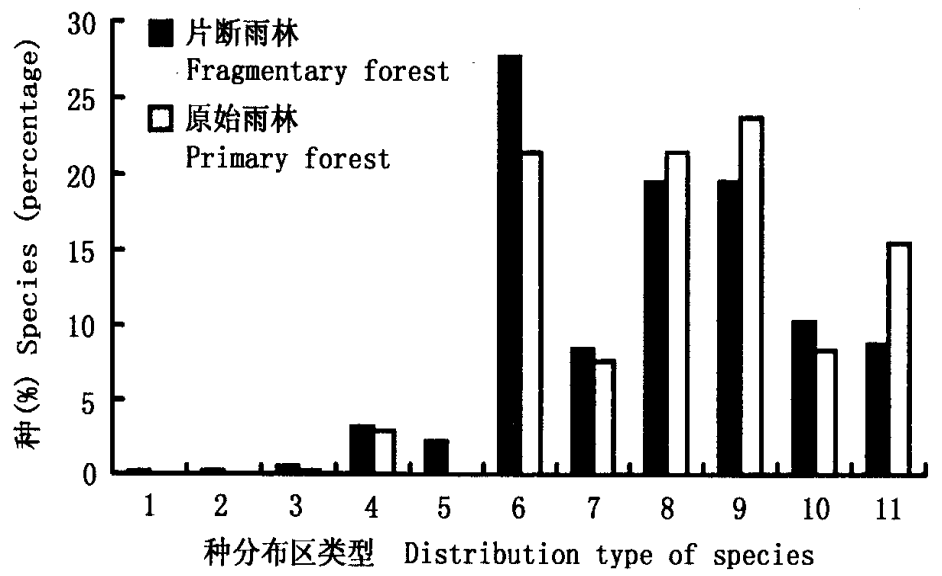

1. 全热带分布; 2 . 热带亚洲 至热带美洲间断分布; 3. 旧 世界热带分布; 4 . 热带亚洲 至大洋洲分布; 5 . 热带亚洲 至热带非洲分布; 6 . 印度一 马亚西亚; 7. 大陆东南亚一 马来西亚 (东南亚分布) ; 8 . 南亚一大陆东南亚; 9. 大陆 东南亚至华南; 10 . 中国西南 至东南部分布; 11 . 云南特有 分布。

1. Pantropic; 2. Tropical Asia and Tropical America disjunct; 3. Old World Tropics; 4 . Tropical Asia and Tropical Australia:5. Tropical Asia to Tropical Africa; 6. India-Malesia; 7. Mainland SE. Asia to Malesia; 8. S. Asia to Mainland SE Asia; 9. Mainland SE. Asia to S. China; 10. SW. to SE. China; 11. Endemic to Yunnan.

图 2 片断雨林与原始雨林植物区系种地理成分比较

Fig. 2 Comparison of distribution types of species between the fragments and continuous primary forests 
致谢 蔡琳女士帮助整理资料、文字录入,曹敏先生在学术讨论上给予很大帮助, 谨此致 谢。

\section{参 考 文 献}

许再富, 朱华, 杨岗, 1998. 片断热带雨林的 岛屿效应”与物种多样性消长规律研究. 中国科学院生物多样

性委员会 (编) ,生物多样性与人类未来. 北京:中国林业出版社. 237 252

吴征镒,王荷生,1983. 中国自然地理—植物地理 (上册), 北京:科学出版社, 30 31

吴征镒,1991.中国种子植物的分布类型.云南植物研究 (增刊 IV) : 1 139

朱华,许再富,王洪,李保贵,刘宏茂,1993. 西双版纳傣族 龙山”植被的研究. 热带植物研究论文报告集 (第二集) :14 31

朱华, 许再富, 王洪, 李保贵, 1997. 西双版纳傣族 龙山”片断热带雨林植物多样性的变化研究. 广西植物, $17(3): 213 \sim 219$

Bierregaard R O, Lovejoy T E, 1989. Effecs of forest fragmentation on Amazonian understory bird communities. Acta A manzonica, $19: 215 \sim 241$

Fonseca de Souza o. Brown V K,994. Effects of habitat fragmentation on Amazonian termite communities. Journal of Tropical Ecology, $10: 197 \sim 206$

Fox B J , Taylor J E, Fox M D, Williams C, 1997. Vegetation changse across edes of rainforest remnants. Bio logical Conseruation, $82: 1 \sim 13$

Kattan G H, Alvarez lopez H, Giraldo M, 1994. Forest fragmentation and vird extinctions San Antonio eighty year later. Conseruation Biology, $8: 138 \sim 146$

Klein B C, 1989. Effects of forest fragmentation on dung and carrion beetle communities in central Amazonia. E cology, $70: 1715 \sim 1725$

Laurance W F, 1991. Edge effects in tropical forest fragments :application of a model for the design of nature reserves. Biological Conseruation, $57: 205 \sim 219$

Laurance W F, 1994. Rainforest fragmentation and the Structute of small mammal communities in tropical Queens land. Biological Conseruation, $69: 23 \sim 32$

Laurance W F, Bierregaard R O , 1997. Tropical Forest Remnants Ecology, Management, and Conservation of Fragmented Communities. The University of Chicago Press

Laurance W F, Ferreira L V, Merona J M R, Laurance S G, 1998. Rain forest fragmentation and the dynamics of Amazonian tree communities. Ecology, 79(6):2032 2040

Leigh E G, Wright Jr S J , Herre E A, Putz F E, 1993. The decline of tree diversity on newly isolated tropical is lands : a test of a null hypothesis and some impications. Evolutionary Ecology, $7: 76 \sim 102$

Malanson G P, Cairns D M , 1997. Effects of dipersal, population delays, and forest fragmentation on tree migration rates. Plant Ecology, $131: 67 \sim 79$

Malcom J R , 1994. Edge effects in central Amazonian forest fragments. Ecology, $75: 2438 \sim 2445$

Murcia C, 1995. Edge effects in fragmented forests :implications for conservation. Trends in Ecology and Evolution, $10: 58 \sim 62$

Oliveira-Filho A T, Mello J M de, Scolforo J R S, 1997. Effects of past disturbance and edges on tree community structure and dynamics within a tragment of tropical semideciduous forest in southeasern Brazil over a five year period. Plant Ecology, $131: 45 \sim 66$

Turner I M , 1996. Species loss in fragments of tropical rain forest : a review of the evidence. Journal of A pplied Ecology, $33: 200 \sim 209$

Williams-Linera G, 1992. Vegetation structure and environmental conditions of forest edges in Panama. Journal of Ecology, 1992, $78: 356 \sim 373$ 